\title{
Parents Attending a Family Weight Management Program Perceive Similar Home Fruit and Vegetable Accessibility, but Greater Child Proxy Agency and Physical Activity Opportunity
}

\author{
Richard R. Rosenkranz, Karly. S. Geller, and David. A. Dzewaltowski \\ Community Health Institute, Kansas State University
}

\begin{abstract}
Many children do not meet current guidelines for physical activity and fruit and vegetable consumption, two areas of health-related behavior with links to obesity. Objective: To examine child and parent perceptions of child proxy agency, home physical activity opportunity, and home accessibility of fruits and vegetables. Methods: Dyads $(\mathrm{N}=117)$ of parents and children completed questionnaires for this cross-sectional study. Results: For child proxy agency, fruits and vegetables accessibility, and physical activity opportunity, the parent and child perceptions were significantly related. Parent ratings of physical activity opportunity and child proxy agency were significantly greater than child ratings. Perceptions of both parents and children for proxy agency were associated with fruits and vegetables accessibility and physical activity opportunity. Conclusions: Parents and children hold similar, yet distinct perceptions of physical activity opportunity and child proxy agency. Perceptions of child proxy agency are associated with obesity-related home environmental characteristics.
\end{abstract}

(C) 2007 Californian Journal of Health Promotion. All rights reserved.

Keywords: Home, Fruits and Vegetables, Physical Activity, Proxy Agency

Obesity has reached epidemic levels (Janssen et al., 2005; Wang, Monteiro, \& Popkin, 2002) and home environments have been shown as a strong influence on children's weight status (Birch \& Davison, 2001; Jago, Baranowski, Baranowski, Thompson, \& Greaves, 2005; Strauss \& Knight, 1999). Concurrent with the rise in obesity has been the failure of children to meet guidelines for obesity-protective behaviors such as regular physical activity and the consumption of fruits and vegetables (Centers for Disease Control and Prevention (CDC), 2003; Eaton et al., 2006; Munoz, Krebs-Smith, Ballard-Barbash, \& Cleveland, 1997). For children to meet these guidelines and avoid obesity, healthy opportunities should be available and accessible in the home environment (Blanchette \& Brug, 2005; Sallis et al., 2006).

Bandura (1989; 2000; 2006) noted that individuals do not always have direct control over environmental factors that affect their behavior, and that they rely on others to help achieve a desired objective. Bandura called this reliance on others proxy agency. Based on the concepts of Social Cognitive Theory (Bandura, 1986; 1989), perceptions of environmental characteristics have a reciprocally deterministic relationship with proxy agency. Children are often reliant on parents and other caregivers to assist them in performing a desired behavior, and parents have been described as gatekeepers to physical activity and fruit and vegetable intake, because children may not be able to meet current health behavior guidelines without parental help (Golan \& Crow, 2004; Golan, Kaufman, \& Shahar, 2006). Depending on the expectations and assigned responsibilities of each family member in a weight management program, the degree to which parents and children similarly perceive the child's proxy agency may impact the success of behavioral and environmental changes in family weight management. 
Individual perceptions of environmental characteristics can be differentiated from more objective measures of environments, but both subjective and objective aspects are likely to influence behavior (Sallis et al., 2006). Although studies have noted the interplay of parent and child perceptions toward health determinants (Dempsey, Kimiecik, \& Horn, 1993; Kimiecik, Horn, \& Shurin, 1996; Kimiecik \& Horn, 1998), family weight management programs often assess only the parent's perception. Little research exists on the concordance of parent and child individual perceptions, and it is not known whether children perceive home environmental characteristics related to health in similar ways as parents, or whether additional insights can be gained by assessing children as well as parents. Therefore, the present study's purpose was to examine the individual perceptions of children and parents regarding physical activity (PA) opportunity, Fruit-Juice-Vegetable (FJV) accessibility, and children's proxy agency (CPA) toward PA and FJV. Our study tested three hypotheses: 1) Parent and child homeenvironment perceptions are positively associated; 2) Perceptions of CPA, FJV accessibility, and PA opportunity are higher in parents; and 3) Parent and child perceptions of CPA are associated with FJV accessibility and PA opportunity.

\section{Method}

Dyads $(\mathrm{N}=117)$ of parents (mean age $38.7, \mathrm{SD}$ $=6.6,77 \%$ mothers, 91\% Caucasian) and their children (mean age 11.4, $\mathrm{SD}=1.4$, ranging 9$16,53 \%$ female, $84 \%$ Caucasian) were recruited through advertisements for a free educational program on healthy eating, physical activity, and weight management. Non-dyad participants and those not completing the questionnaire were excluded from analysis $(\mathrm{N}=240)$. Informed consent and questionnaire data from children and parents were collected at the first meeting of the program. All obtained data, including demographics, were self-reported on the questionnaire. This project was approved by the IRB at the authors' university.

The FJV accessibility scale consisted of the three accessibility items from the previously validated fruit and vegetable availability/accessibility scale (Hearn et al., 1998). Parent and child versions each contained three dichotomous (yes/no) items, indicating presence or absence of recent accessibility. Items included: 1) In the past week, were there vegetables in the refrigerator prepared so you (your child) could readily use them in a meal?; 2) In the past week, were there fruits or vegetables on the kitchen counter or somewhere out in the open?; 3) In the past week, was $100 \%$ fruit juice, fruit or cut-up vegetables on the front shelf of the refrigerator as a snack? As a scale, the internal consistency of these three-items was relatively low ( $\alpha=.418$ for children, $\alpha=.542$ for parents).

Physical activity opportunity was assessed with items used in previous studies and modeled after similar scales (Hearn et al., 1998; Ryan \& Dzewaltowski, 2002). Parent and child versions each contained three dichotomous items, indicating presence or absence of recent opportunity. Items included: 1) In the past week, was there a place available to you (your child) where you (he/she) could be physically active?; 2) In the past week, did you have help from your parent (did you help your child) in finding, planning, or getting a ride to/from a physical activity for you (him/her) to do?; 3) In the past week, were you physically active with your child? As a scale, the internal consistency of these three-items was relatively low ( $\alpha=.454$ for children, $\alpha=.585$ for parents).

Child proxy agency was measured using two sets of five items, one for FJV (CPA-FJV), and the other for PA (CPA-PA). CPA-FJV items (Reynolds, Yaroch, Franklin, \& Maloy, 2002) were very slightly edited for clarity from previous work. Sample items included: (child) How confident are you that you can get your parents to help you include your favorite fruits in your lunch?; (parent) How confident are you that your child can get you to help include your child's favorite fruits in his/her lunch?; The CPA-PA items were previously validated (Karteroliotis, Dzewaltowski, Gyurcsik, Estabrooks, \& Johnson, 2004). Sample items included: (child) How confident are you that you can get your parents to help you find a place where you can be physically active?; (parent) 
How confident are you that your child can get you to help find a place where he/she can be physically active? Principal components analysis confirmed the presence of two underlying proxy agency factors for PA and FJV. Items were rated on a five-point scale, and internal reliabilities were adequate $(\alpha=.86-.90)$.

The Statistical Package for Social Sciences (SPSS 12.0) was used for all data reduction and analysis procedures. To test hypothesis 1 , that parent perceptions and child perceptions of selfefficacy and availability are positively associated, Pearson product moment correlations were run. To test hypothesis 2, that parent perceptions for self-efficacy and FJV availability and PA opportunity are higher than those of children, paired sample t-tests were used. To test hypothesis 3, that parent and child FJV availability and PA opportunity are associated with CPA, linear regression analysis was employed, controlling for parent education and family income level.

\section{Results}

Table 1 displays the results for tests of hypotheses one and two. There were significant positive correlations between parent and child perceptions of FJV accessibility $(r=.497, \mathrm{p}=$ $.001)$, PA opportunity $(\mathrm{r}=.367, \mathrm{p}=.001)$, CPAFJV $(r=.202, p=.033)$, and CPA-PA $(r=.224$, $\mathrm{p}=.017)$. Significant differences were found between parent and child perceptions of PA opportunity $(\mathrm{t}=1.99, \mathrm{p}=.05)$, CPA-PA $(\mathrm{t}=$ $2.72, \mathrm{p}=.008)$, and CPA-FJV $(\mathrm{t}=3.69, \mathrm{p}<$ $.001)$, but differences were not significant for FJV accessibility $(\mathrm{t}=.81, \mathrm{p}=.421)$.

Table 1

Comparison of parent and child perceptions of FJV accessibility, PA opportunity, and child proxy agency $(n=117)$

\begin{tabular}{|l|c|c|c|c|}
\hline Measured Variables & $\begin{array}{c}\text { Parent Perception } \\
(\mathrm{M} \pm \mathrm{SD})\end{array}$ & $\begin{array}{c}\text { Child } \\
\text { Perception } \\
(\mathrm{M} \pm \mathrm{SD})\end{array}$ & $\begin{array}{c}\text { Parent-child } \\
\text { difference }\end{array}$ & $\begin{array}{c}\text { Parent-child } \\
\text { correlation }\end{array}$ \\
\hline FJV availability & $2.25 \pm .92$ & $2.18 \pm .90$ & $t=.81$ & $\mathrm{r}=.497^{*}$ \\
\hline PA opportunity & $2.23 \pm .91$ & $2.03 \pm .92$ & $t=1.99^{*}$ & $\mathrm{r}=.367^{*}$ \\
\hline CPA-PA & $19.06 \pm 4.3$ & $17.49 \pm 5.3$ & $t=2.72^{*}$ & $\mathrm{r}=.202^{*}$ \\
\hline CPA-FJV & $19.99 \pm 4.8$ & $17.79 \pm 5.4$ & $t=3.69^{*}$ & $\mathrm{r}=.224^{*}$ \\
\hline
\end{tabular}

Note: FJV accessibility and PA opportunity perceptions were on a 0 to 3 scale. CPA-PA and CPA-FJV perceptions were on a 5 to 25 scale, ${ }^{*} \mathrm{p}<.05$.

Two linear regression analyses, controlling for parent income and education, tested the hypothesis that parent and child CPA are associated with FJV accessibility and PA opportunity. The results showed that parent CPA-FJV $(\beta=.365, p<.001)$ and child CPAFJV $(\beta=.273, p=.005)$ were positively associated with FJV accessibility, the final model explaining 26 percent of the accessibility variance $\left(\mathrm{R}^{2}=.264, \mathrm{p}<.001\right)$. The second regression results showed that parent CPA-PA $(\beta=.308, p=.002)$ and child CPA-PA $(\beta=$ $.234, \mathrm{p}=.02)$ were positively associated with
PA opportunity, the final model explaining 18 percent of the PA opportunity variance $\left(\mathrm{R}^{2}=\right.$ $.177, \mathrm{p}<.001)$.

\section{Discussion}

Our results showed that parent and child perceptions were weakly but significantly associated, and that ratings tended to be higher among parents. Both parent and child perceptions of CPA were associated with FJV accessibility and PA opportunity. Parents and their children shared similar perceptions of FJV accessibility, less similar perceptions of PA 
opportunities, and more divergent perceptions of CPA for PA and FJV. Sawin and associates (2006) reported a similar pattern between parents and adolescents, with agreement tapering from objective to more subjective domains. Bere and Klepp (2004) found parents rated FJV accessibility higher than did children, but unlike our study, found children rated their abilities higher than did parents. In the present study, proxy agency perceptions of parents and children were associated with the home environment, a finding similar to previous work (Cullen et al., 2003), reporting that childperceived availability and parent-perceived accessibility were associated with child FJV consumption.

Our results, along with a growing body of literature on ecological influence, suggest that weight management programs could aim to help families make changes to the home environment and thereby alter both perceptions and behavior. Future work should also seek to determine whether influencing proxy agency is a necessary step in attempts to improve health behavior in families.

The validity of the present study is tempered by a number of limitations, including a reliance on self-report measures, the use of a convenience sample, and non-comprehensive measurements of PA opportunity and FJV accessibility.
Though our reliability estimates are higher than reported elsewhere $(\alpha<.40$, Cullen et al., 2000) the low values observed for measures of FJV accessibility and PA opportunity indicate these indices may not fully measure the variables of interest. Both of these measures will need further work to improve psychometric properties. Further, method variance may account for some of the associations observed between variables. Also, we cannot rule out the possibility of a social desirability bias, especially on the part of parents. Thus, these findings should be interpreted with caution. Future research is needed to determine whether comprehensive and objective measures of the home environment show similar patterns to those in this study.

Overall, these results suggest that parents and children may have related but unique perceptions of the home environment and of children's proxy agency. Practitioners and families may benefit by considering the perceptions of both parents and children in weight management programs. Stemming from this area, future programs could be designed to target children's asking skills, and to bolster parents' abilities to create better home environments by providing more opportunities for physical activity and making fruits and vegetables more accessible.

\section{References}

Bandura, A. (Ed.). (1986). Social foundations of thought and action: A social cognitive theory. Englewood Cliffs

Bandura, A. (2000). Exercise of human agency through collective efficacy. Current Directions in Psychological Science, 9(3), 75-78.

Bandura, A. (2006). Toward a psychology of human agency. Perspectives on Psychological Science, 1, 164-180.

Bandura, A. (1989). Human agency in social cognitive theory. The American Psychologist, 44, $1175-$ 1184.

Bere, E., \& Klepp, K. I. (2004). Correlates of fruit and vegetable intake among Norwegian schoolchildren: Parental and self-reports. Public Health Nutrition, 7, 991-998.

Birch, L. L., \& Davison, K. K. (2001). Family environmental factors influencing the developing behavioral controls of food intake and childhood overweight. Pediatric Clinics of North America, 48, 893-907.

Blanchette, L., \& Brug, J. (2005). Determinants of fruit and vegetable consumption among 6-12-year-old children and effective interventions to increase consumption. Journal of Human Nutrition and Dietetics, 18, 431-443. 
Centers for Disease Control and Prevention (CDC). (2003). Physical activity levels among children aged 9-13 years--United States, 2002. Morbidity and Mortality Weekly Report, 52, 785-788.

Cullen, K. W., Baranowski, T., Owens, E., Marsh, T., Rittenberry, L., \& de Moor, C. (2003). Availability, accessibility, and preferences for fruit, $100 \%$ fruit juice, and vegetables influence children's dietary behavior. Health Education \& Behavior, 30, 615-626.

Cullen, K., Baranowski, T., Rittenberry, L., Cosart, C., Owens, E., Hebert, D., de Moor, C. (2000). Socioenvironmental influences on children's fruit, juice and vegetable consumption as reported by parents: Reliability and validity of measures. Public health nutrition, 3, 345-356.

Dempsey, J. M., Kimiecik, J. C., \& Horn, T. S. (1993). Parental influence on children's moderate to vigorous physical activity participation: An expectancy-value approach. Pediatric Exercise Science, 5, 151-167.

Eaton, D. K., Kann, L., Kinchen, S., Ross, J., Hawkins, J., Harris, W. A., Lowry, R., McManus, T., Chyen, D., Shanklin, S., Lim, C., Grunbaum, J. A., Wechsler, H. (2006). Youth risk behavior surveillance--United States, 2005. Morbidity and Mortality Weekly Report, Surveillance Summary, 55(5), 1-108.

Golan, M., \& Crow, S. (2004). Parents are key players in the prevention and treatment of weight-related problems. Nutrition Reviews, 62(1), 39-50.

Golan, M., Kaufman, V., \& Shahar, D. R. (2006). Childhood obesity treatment: Targeting parents exclusively v. parents and children. The British Journal of Nutrition, 95, 1008-1015.

Hearn, M. D., Baranowski, T., Baranowski, J., Doyle, C., Smith, M., Lin, L. S., Resnicow, K. (1998). Environmental influences on dietary behavior among children: Availability and accessibility of fruits and vegetables enable consumption. Journal of Health Education, 29(1), 26-32.

Jago, R., Baranowski, T., Baranowski, J. C., Thompson, D., \& Greaves, K. A. (2005). BMI from 3-6 y of age is predicted by TV viewing and physical activity, not diet. International Journal of Obesity (London), 29, 557-564.

Janssen, I., Katzmarzyk, P. T., Boyce, W. F., Vereecken, C., Mulvihill, C., Roberts, C., Currie, C. (2005). Comparison of overweight and obesity prevalence in school-aged youth from 34 countries and their relationships with physical activity and dietary patterns. Obesity Reviews, 6, 123-132.

Karteroliotis, K., Dzewaltowski, D. A., Gyurcsik, N. C., Estabrooks, P. A., \& Johnson, J. A. (2004). Task and environmental change self-efficacy for physical activity scale: Analysis of factorial invariance across gender. Medicine \& Science in Sports \& Exercise, 36(5), S62.

Kimiecik, J. C., \& Horn, T. S. (1998). Parental beliefs and children's moderate-to-vigorous physical activity. Research Quarterly for Exercise and Sport, 69, 163-175.

Kimiecik, J. C., Horn, T. S., \& Shurin, C. S. (1996). Relationships among children's beliefs, perceptions of their parents' beliefs, and their moderate-to-vigorous physical activity. Research Quarterly for Exercise and Sport, 67, 324-336.

Munoz, K. A., Krebs-Smith, S. M., Ballard-Barbash, R., \& Cleveland, L. E. (1997). Food intakes of US children and adolescents compared with recommendations. Pediatrics, 100(3 Pt 1), 323-329.

Reynolds, K. D., Yaroch, A. L., Franklin, F. A., \& Maloy, J. (2002). Testing mediating variables in a school-based nutrition intervention program. Health Psychology, 21(1), 51-60.

Ryan, G. J., \& Dzewaltowski, D. A. (2002). Comparing the relationships between different types of selfefficacy and physical activity in youth. Health Education \& Behavior, 29, 491-504.

Sallis, J. F., Cervero, R. B., Ascher, W., Henderson, K. A., Kraft, M. K., \& Kerr, J. (2006). An ecological approach to creating active living communities. Annual Review of Public Health, 27, 297-322.

Sawin, K. J., Hayden Bellin, M., Builta, E., Vasel, L., Buran, C. F., \& Brei, T. J. (2006). Cross-informant agreement between adolescents with myelomeningocele and their parents. Developmental Medicine and Child Neurology, 48, 188-194.

Strauss, R. S., \& Knight, J. (1999). Influence of the home environment on the development of obesity in children. Pediatrics, 103(6), e85. 
Wang, Y., Monteiro, C., \& Popkin, B. M. (2002). Trends of obesity and underweight in older children and adolescents in the United States, Brazil, China, and Russia. American Journal of Clinical Nutrition, 75, 971-977.

\section{Acknowledgements}

The authors of this manuscript have no competing interests or conflicts of interest to declare. Community Health Institute is funded by grants from the United States Department of Agriculture, Robert Wood Johnson Foundation, Sunflower Foundation, and Kansas Health Foundation.

Author Information

Richard R. Rosenkranz, M.A., M.S.*

Community Health Institute

8 Natatorium

Kansas State University

Manhattan, KS 66506

Ph.: 785-532-0709

Fax.: 785-532-7733

E-Mail: Ricardo@ksu.edu

Karly. S. Geller, M.S.

Community Health Institute

Kansas State University

David. A. Dzewaltowski, Ph.D.

Community Health Institute

Kansas State University

* corresponding author 